Article

\title{
Coal and Coalbed Methane Co-Extraction Technology Based on the Ground Movement in the Yangquan Coalfield, China
}

\author{
Guozhong Hu ${ }^{1,2,3}$, Jialin Xu ${ }^{1,2, *}$, Fuxi Zhang ${ }^{3}$, Changchun Zhao ${ }^{3}$, Wei Qin ${ }^{2}$ and Yiran Zhu ${ }^{1}$ \\ 1 School of Mines, Key Laboratory of Deep Coal Resource Mining, Ministry of Education of China, \\ China University of Mining and Technology, Xuzhou 221116, Jiangsu, China; \\ E-Mails: gzhu@cumt.edu.cn (G.H.); zyr2015@cumt.edu.cn (Y.Z.)
}

2 State Key Laboratory of Coal Resources and Safe Mining, China University of Mining and Technology, Xuzhou 221116, Jiangsu, China; E-Mail: qw198427@cumt.edu.cn

3 Post-Doctoral Research Station, Yangquan Coal Industry (Group) CO., LTD, Yangquan 045000, Shanxi, China; E-Mails: ymfxzhang@gmail.com (F.Z.); ymcczhao@gmail.com (C.Z.)

* Author to whom correspondence should be addressed; E-Mail: cumtxj1@cumt.edu.cn; Tel./Fax: +86-516-8388-5581.

Academic Editor: Vasily Novozhilov

Received: 26 May 2015 / Accepted: 2 July 2015 / Published: 9 July 2015

\begin{abstract}
The Yangquan coalfield is one of the typical highly gassy mining areas in China. However, its coal seams are of lower permeability, which are not conductive to coalbed methane (CBM) drainage. In this study, based on the theory of the ground movement, we analyzed the principle of coal and CBM coextraction in the Yangquan coalfield, and established the technology system of coal and CBM coextraction which was further implemented in the coal and CBM coextraction in the Yangquan coalfield. The coal and CBM coextraction technologies based on the "pressure-relief and permeability-increase" effect caused by the mining overburden movement can optimally ensure the safe and efficient mining and improve the gas drainage rate. A series of developed coal and CBM coextraction technologies for the Yangquan coalfield were mainly characterized by the high-level gas drainage roadway. This reached a maximum gas drainage amount of $270,000 \mathrm{~m}^{3} /$ day for single drainage roadway and a pressure-relief gas drainage rate of $>90 \%$. Those technologies significantly improved the gas drainage effect safely and efficiently achieving the coal and CBM coextraction.
\end{abstract}


Keywords: ground movement; Yangquan coalfield; coal and coalbed methane coextraction; gas drainage; key strata movement

\section{Introduction}

Coalbed methane (CBM) is a symbiotic or associated gas present in the coal seam with methane as its main component. In traditional coal mining, CBM is considered a type of hazardous gas, not only because of the danger of explosions and gas outbursts, but also because of serious threat to the safety of mine production [1-6]. In contrast, $\mathrm{CH}_{4}$, the main ingredient of $\mathrm{CBM}$, is a greenhouse gas, whose greenhouse effect is $\sim 21-23$ times as strong as that of $\mathrm{CO}_{2}$ [7-10]. However, the amount of gas emissions to the atmosphere because of coal mining is $\sim 19.4$ billion $\mathrm{m}^{3}$ per year in China, resulting in both the waste of resources and environmental pollution [11]. Moreover, CBM is also a clean and efficient energy source. According to the statistics of Sun [11], the CBM reserves in China are 36.81 trillion $\mathrm{m}^{3}$, with a considerable amount of onshore conventional natural gas resources. Therefore, CBM should be considered as a type of resource to extract and utilize so that the adverse effects of CBM on the safety of the coal production and atmospheric environment can be ultimately eliminated.

At present, the main countries extracting CBM worldwide are China, the USA, Australia, Germany, and Poland [12-14]. Among them, the coal seams in America and Australia are of little depth and high permeability, and surface well predrainage and underground directional long borehole drainage technologies are their major and minor strategies, respectively. Part of Germany and Poland are similar to the coal seam conditions in Chinese mining areas; however, their yields are low and the number of underground coal seams is relatively small; and the gas drainage is mainly dependent on the underground cross-measure boreholes gas drainage technology [1-6,15]. In contrast, the Chinese coal seams are of larger depth and high ground stress; therefore, underground drainage is the main approach to extract CBM. The Yangquan coalfield is one of the most famous typical high-gas coal mines and the largest mining area causing greenhouse gas emissions in China [16]. The coal seams of the Yangquan coalfield are of low permeability, low reservoir pressure, and low gas saturation, resulting in a low rate of the coal seam gas drainage. Therefore, an effective CBM extraction, improving the gas drainage rate and reducing mine greenhouse gas emissions, has become an urgent problem to be solved in the coal production in the Yangquan coalfield.

The system of original coal seam and surrounding rock and gas fluid stays in the equilibrium prior to the mining. During the mining process, the surrounding coal and rock of the working face are deformed under the effect of the mining pressure and their mechanical parameters, including the porosity, permeability coefficient of the coal change with the deformation, thus affecting the gas flow in the coal seam [17,18]. Therefore, based on the effect of pressure relief caused by the ground movement in the mining process, the coal and CBM were considered as mineral resources for simultaneous extraction in the mining process, forming two complete coal mining and gas drainage systems, named "coal and CBM coextraction technology" [19]. This can achieve the safe and efficient mining of the working face. The coal and CBM coextraction is one of the main contents of the green mining technology for coal mines and has become the research hotspot of gas drainage technology in high-gas coal mines in 
China [20-23]. In this study, the Yangquan coalfield was studied as an example by the analysis of the coal seam and gas occurrence characteristics of this mining area, and the coal and CBM coextraction technology based on the ground movement of the Yangquan coalfield were applied. Moreover, the implementation effect of the coal and CBM coextraction and gas utilization technology in the Yangquan coalfield was investigated and is summarized. This study may provide a reference for the gas extraction and utilization of high-gas coal mines and has important theoretical and practical significance for improving the gas drainage effect, controlling and preventing coal mine gas disasters, and reducing greenhouse gas emissions.

\section{Gas Occurrence Characteristics in the Yangquan Coalfield}

\subsection{Coal Occurrence Characteristics}

The Yangquan coalfield is located on the northeastern side of the Qinshui basin in Shanxi Province, on the west wing of the anticline of the Taihang Mountains. It is basically a monocline towards the northeast, tilting to the southwest. Its main strata bearing coal are the Carboniferous Taiyuan formation and the Permian Shanxi formation. The total thickness of the coal strata in this mining is $180 \mathrm{~m}$; the total thickness of the coal seam is in the $\sim 13-15 \mathrm{~m}$ range, with a depth in the $\sim 150-500 \mathrm{~m}$ range; the dip angle of the coal seam is generally in the $5^{\circ}-10^{\circ}$ range. This coal mining area contains 16 layers, of which the main coal seams were $3 \#, 12 \#$, and $15 \#$, and the local recoverable coal seams were $6 \#, 8 \#$, and 9\#. These coal seams are higher metamorphic grade coal anthracite, as shown in Figure 1 [24].

\begin{tabular}{|c|c|c|c|}
\hline Strata & Column & Thickness (m) & Coal-rock name \\
\hline \multirow{11}{*}{$\begin{array}{c}\text { Shanxi } \\
\text { formation, } \\
\text { Permian }\end{array}$} & \multirow{2}{*}{ 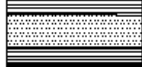 } & 0.41 & $1 \#$ coal seam \\
\hline & & 6.10 & Sandstone, mudstone \\
\hline & \multirow{3}{*}{$==$} & 0.35 & $2 \#$ coal seam \\
\hline & & 17.00 & Sandstone, mudstone \\
\hline & & 1.89 & $3 \#$ coal seam \\
\hline & E三::三三 & 4.50 & Sandy mudstone \\
\hline & \multirow{3}{*}{ 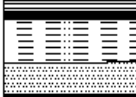 } & 0.46 & $4 \#$ coal seam \\
\hline & & 2.50 & Mudstone \\
\hline & & 0.40 & $5 \#$ coal seam \\
\hline & \multirow[b]{3}{*}{$\Rightarrow=m=$} & 5.10 & Sandstone, mudstone \\
\hline & & 0.20 & $6 \#$ coal seam \\
\hline \multirow{16}{*}{$\begin{array}{c}\text { Taiyuan } \\
\text { form ation, } \\
\text { Carboniferous }\end{array}$} & & 20.00 & Sandstone, m udstone \\
\hline & \multirow{2}{*}{ 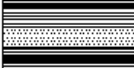 } & 1.00 & $7 \#$ coal seam \\
\hline & & 7.12 & Mudstone \\
\hline & 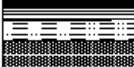 & 1.40 & $8 \#$ coal seam \\
\hline & \multirow{2}{*}{ 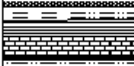 } & 19.33 & Sandstone, sandy mudstone \\
\hline & & 0.59 & $9 \#$ coal seam \\
\hline & $=-1=1$ & 24.00 & $\begin{array}{l}\text { Sandstone, sandy mudstone, } \\
\text { limestone }\end{array}$ \\
\hline & \multirow{2}{*}{ 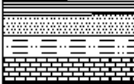 } & 0.31 & $11 \#$ coal seam \\
\hline & & 10.00 & Sandstone, sandy mudstone \\
\hline & \multirow{2}{*}{ 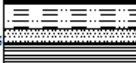 } & 1.40 & $12 \#$ coal seam \\
\hline & & 10.10 & Sandstone, mudstone, lim estone \\
\hline & \multirow{3}{*}{ 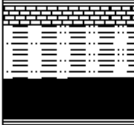 } & 0.54 & $13 \#$ coal seam \\
\hline & & 30.00 & $\begin{array}{l}\text { Sandstone, sandy mudstone, } \\
\text { limestone, mudstone }\end{array}$ \\
\hline & & 6.50 & $15 \#$ coal seam \\
\hline & 三..”: $\equiv$ & 7.60 & Mudstone, fine sandstone \\
\hline & 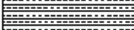 & 0.49 & 16 \# coal seam \\
\hline
\end{tabular}

Figure 1. Combined geological column of coal seams. 
The thickness of the $9 \#$ coal seam is $0.59 \mathrm{~m}$, and the local recoverable region thickness of this coal seam is up to $\sim 2 \mathrm{~m}$ and is located $76.35 \mathrm{~m}$ away from the coal seam roof of the $15 \#$ coal seam, as shown in Figure 1. A gassy layer of K4 limestone with a thickness of $\sim 2 \mathrm{~m}$ exists $52.35 \mathrm{~m}$ away from the roof of the $15 \#$ coal seam at $22 \mathrm{~m}$ beneath the $9 \#$ coal seam. The thickness of the $12 \#$ coal seam is $1.4 \mathrm{~m}$ and it is $41 \mathrm{~m}$ away from the roof of the 15\# coal seam. A gassy layer of K3 limestone with a thickness of $2.84 \mathrm{~m}$ exists $7 \mathrm{~m}$ beneath the $12 \#$ coal seam and $30.54 \mathrm{~m}$ away from the roof of the $15 \#$ coal seam. The $15 \#$ coal seam, with an average thickness of $6.5 \mathrm{~m}$, had a stable coal with a complex structure; the immediate roof of the 15\# coal seam is black sandy shale, with a thickness in the $\sim 0-6.5 \mathrm{~m}$ range and a basic limestone roof; and the floor mainly comprises the same black sandy shale with a thickness in the 7-12 m range, and the basic roof was dark gray sandy shale. Overall, the coal seam in the Yangquan coalfield presents dense structures, high hardness, strong luster, smooth joint surfaces, and low permeability.

\subsection{Coalbed Methane (CBM) Occurrence Characteristics}

All the coal seams in the Yangquan coalfield contain methane, and the strata bearing coal is roughly divided into three gas enrichment sections combined with the position of the main mining coal seam, i.e., the gas enrichment section of the $3 \#$ coal seam and adjacent seams, the gas enrichment section of the 12\# coal seam and adjacent seams and K3 and K4 limestone, and the gas enrichment section of the 15\# coal seam and K2 limestone, as shown in Figure 1. In the Yangquan coalfield, the gas content in each coal seam is different and also varies from place to place within the same seam. The gas content and gas pressure of the coal seams were in the $\sim 7.13-32.41 \mathrm{~m}^{3} / \mathrm{t}$ and $\sim 0.25-2.3 \mathrm{MPa}$ range, respectively. The maximum gas pressure in the $9 \#$ and $10 \#$ coal seams declined upward and downward.

The total gas resource reserves in the Yangquan coalfield were 644.8 billion $\mathrm{m}^{3}$; the absolute gas emission was $1918.72 \mathrm{~m}^{3} / \mathrm{min}$; the largest gas emission of a single coal mine was $454.65 \mathrm{~m}^{3} / \mathrm{min}$; the largest gas emission of a single working face was $206 \mathrm{~m}^{3} / \mathrm{min}$; and the average permeability coefficient of the coal seams was $0.000375 \mathrm{mD} /\left(\mathrm{M} \cdot \mathrm{Pa}^{2} \mathrm{~d}\right)$, making the Yangquan coalfield one of the typical coal seams with difficult extraction of gases in China.

\section{The Development of Coal and CBM Coextraction Technology Based on the Ground Movement in the Yangquan Coalfield}

\subsection{The Concept of Coal and CBM Co-Extraction}

Gas in an underground coal mine comes mainly from coal seams and coal measure strata. Over the years, CBM was considered to be a harmful gas, affecting the safety of the underground coal mining. The aims of gas drainage were only to reduce the gas content of coal seams and guarantee the underground mining safety of high-gas coal mines. However, the gas emissions in coal mine areas have increased sharply because of the rapid growth of coal production year after year in China, thereby seriously polluting the atmospheric environment and contributing to the global greenhouse effect. In contrast, $\mathrm{CBM}$ is a clean energy source. Therefore, $\mathrm{CBM}$ is extracted as an energy resource, which has become the new popular consensus [25,26], as shown in Figure 2. 


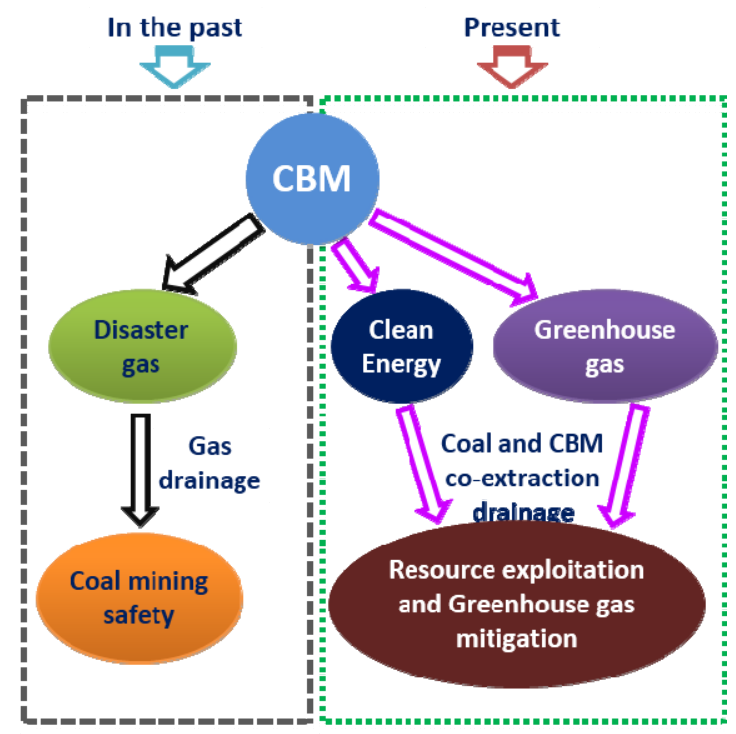

Figure 2. The concept of coal and Coalbed Methane (CBM) coextraction.

However, the coal seams of the Yangquan coalfield are of low permeability, thereby limiting the development of gas drainage technology. Coal mine practices have shown that the ground movement and permeability of the low-permeability coal seam will increase by ten to hundred times, achieving efficient gas drainage. Therefore, in the mining, the CBM can be extracted together with coal as a mineral resource, forming two complete coal mining and gas drainage systems, and the gas can be effectively extracted by the pressure relief effect caused by the ground movement during mining to achieve the safe and efficient mining of a working face, improving the gas drainage rate and reducing greenhouse gas emissions at the same time [19].

\subsection{Principle of Coal and CBM Coextraction Based on the Ground Movement}

The main mining coal seams in the Yangquan coalfield were 3\#, 8\#, 12\#, and 15\#. The coal seams $3 \#, 8 \#$, and $12 \#$ have high gas pressure, high gas content, and low permeability. However, the gas pressure and gas content of the $15 \#$ coal seam were less than those if the other main mining coal seams, and the $15 \#$ coal seam was the first mining coal seam.

With the constant mining of the working face in the $15 \#$ coal seam, the overlying and underlying coal seams would undergo deformation and movement, thus changing the original stress field in the 15\# coal seam forming the abutment pressure zone. It includes the pressure relief zone and the stress concentration zone in the seam [5]. In the pressure-relief zone, the gas pressure of the $15 \#$ coal seam would decrease, resulting in a pressure difference between the wall and the coal seam ahead of it. Then, the gas pressure difference will gradually spread to the front of the wall, thus forming a changed gas pressure gradient and causing a gas flow, finally presenting the "pressure-relief and permeability-increase effect". Moreover, the deformation and fracture of the 15\# coal seam affected by mining can significantly improve the permeability of the coal seam and provide gas flow channels. Therefore, the amount of gas drainage of the abutment pressure zone could be increased significantly. Then, intensively extracting CBM in the abutment pressure zone can provide highly efficient coal and CBM coextraction, improve inseam gas drainage amount, and reduce gas emissions. 
In contrast, the ground movement caused by the mining of the $15 \#$ coal seam changed the stress fields of the overlying and underlying coal seams, resulting in gas pressure relief of the adjacent $3 \#$, $8 \#$, and $12 \#$ coal seams. Simultaneously, the surrounding rocks of the $15 \#$ coal seam were deformed and destroyed because of the changes in the stress field, forming inseam separation fracture and cross-measure vertical broken fissures (Figure 3). Then, the gas-way fracture zone in the overburden of the 15\# coal seam was generated and extended, improving the permeability of the gas flow in the coal and rock, thus providing a large number of flow channels for the pressure-relief gas and continuous desorption conditions, benefiting pressure-relief gas drainage of the adjacent 3\#, 8\#, and 12\# coal seams. According to the test results [27], the Panel K7209 (see Figure 4) in the 3\# coal seam had $~ 70 \%$ gas drainage concentration and $\sim 26.92 \mathrm{~m}^{3} / \mathrm{min}$ gas drainage amounts during mining of the $15 \#$ coal seam.

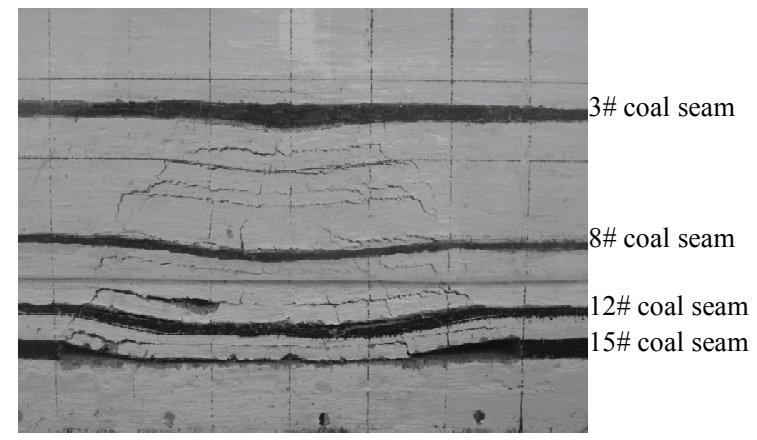

Figure 3. Cracks development of overburden after mining of the $15 \#$ coal seam.

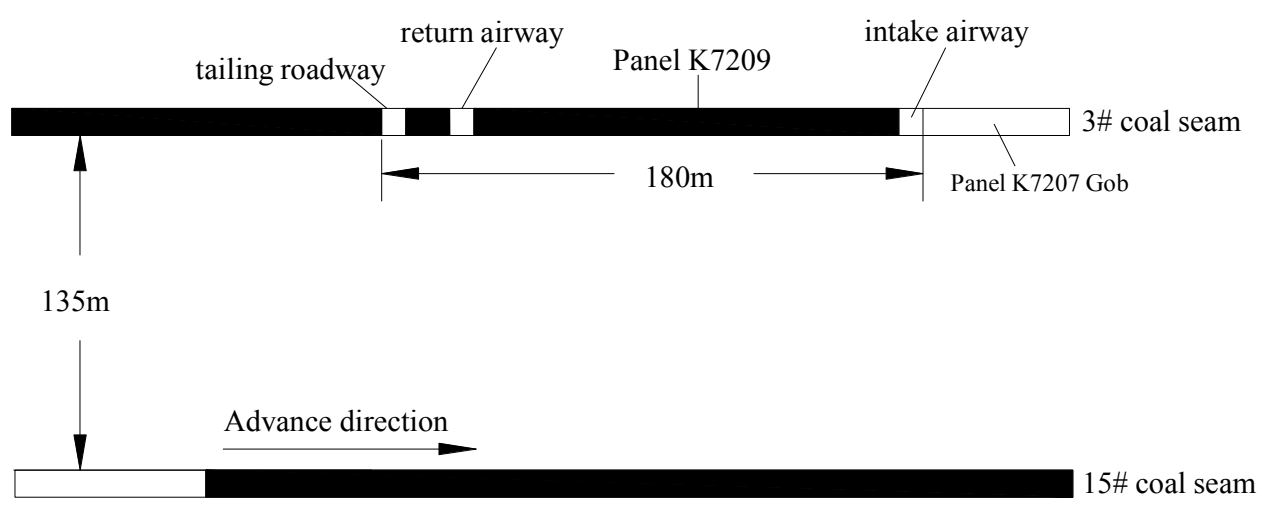

Panel K8206

Figure 4. Schematic diagram of working face layout of these 15\#, 3\# coal seams.

Because of different coal-rock fracture distributions in different regions, the conditions of gas desorption and flow were different. The Yangquan coalfield uses different gas drainage technologies to extract pressure-relief gas in the $15 \#$ coal seam and the adjacent $3 \#, 8 \#$, and $12 \#$ coal seams. These gas drainage technologies reduced the flow of pressure-relief gas of the $3 \#, 8 \#$, and $12 \#$ coal seams to the working face in $15 \#$ coal seam, ensuring safe and efficient mining of the work face in the $15 \#$ coal seam. At the same time, these gas drainage technologies can reduce the gas contents of the $3 \#, 8 \#$, and $12 \#$ coal seams to achieve the safe and efficient mining of the working face in $3 \#, 8 \#$, and $12 \#$ coal seams. Therefore, the overburden movement and pressure-relief effect caused by the mining of the inseam working face under the coal seam group conditions can be used to extract pressure-relief gas from the inseam and adjacent seams to harmonize coal and CBM coextraction, as shown in Figure 5. 


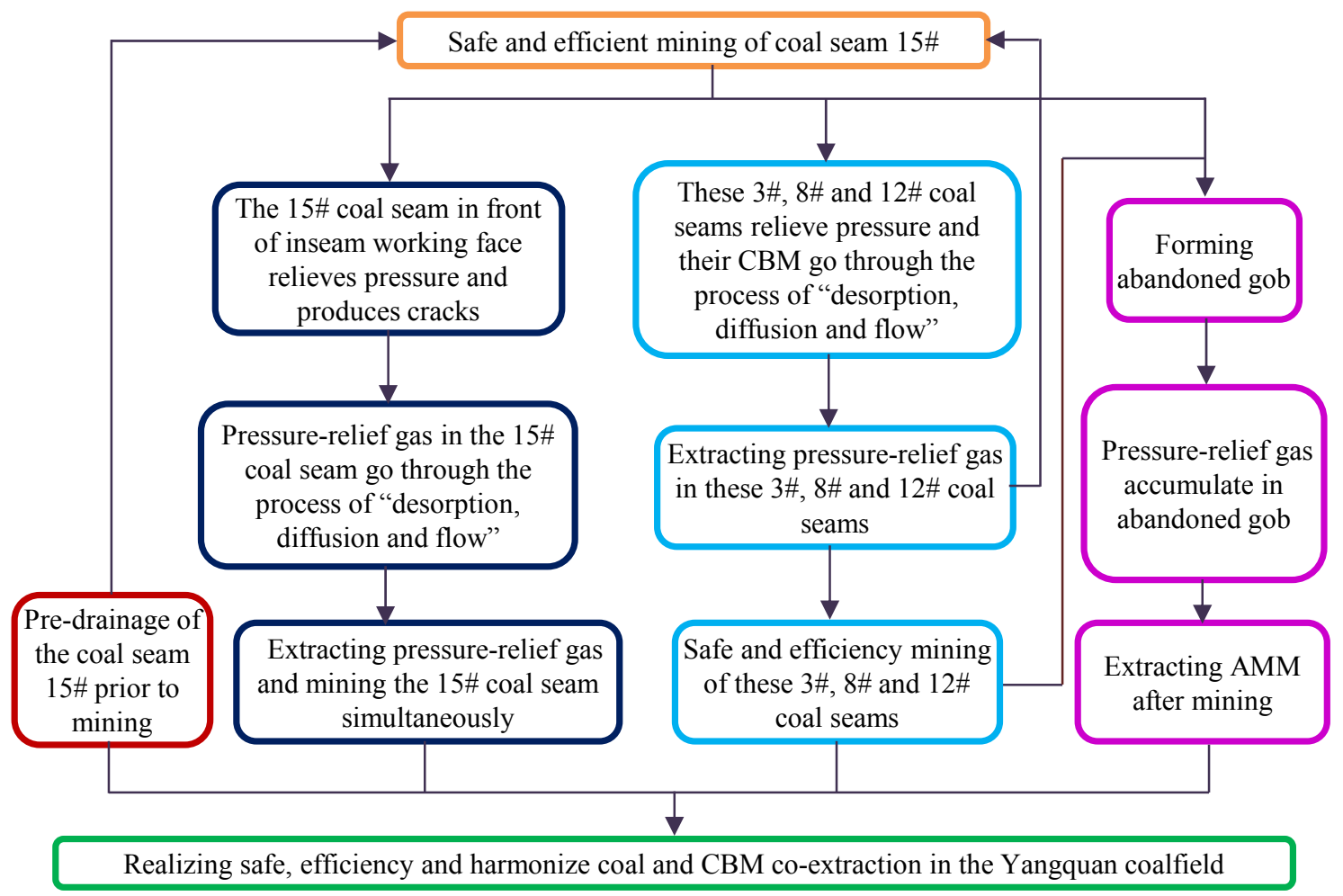

Figure 5. The principle of coal and CBM coextraction based on the ground movement in the Yangquan coalfield.

\subsection{The System of Coal and CBM Co-Extraction Technology in the Yangquan Coalfield}

According to the basic principle of coal and CBM coextraction in the Yangquan coalfield, the coal and $\mathrm{CBM}$ coextraction process was divided in the following stages:

(1) The gas drainage prior to the coal mining, i.e., the predrainage of the CBM in the $15 \#$ coal seam not only reduced the gas content and improved the mining safety, but also enhanced the mining efficiency of the $15 \#$ coal seam.

(2) The coal and CBM coextraction, i.e., the pressure-relief gas of the $15 \#$ coal seam was effectively extracted by the "pressure-relief and permeability-increase effect" caused by the mining of the $15 \#$ coal seam. Simultaneously, based on the mining effect of the $15 \#$ coal seam on the gas pressure-relief law of the adjacent $3 \#, 8 \#$, and 12\# coal seams, the pressure-relief gas of the $3 \#, 8 \#$, and $12 \#$ coal seams was effectively extracted by making full use of the favorable conditions of increasing the permeability of the coal seam.

(3) The gas drainage after the coal mining, i.e., pressure-relief gas in the abandoned gob was extracted after the end of the mining of the working face, panel, or mine to make full use of the gaseous resources.

Therefore, according to the process of coal and CBM coextraction, there are three types of gas drainage technologies corresponding to three stages in this process, namely gas predrainage technology prior to the mining, pressure-relief gas drainage and abandoned mine methane (AMM) drainage technologies, thus forming the technology system of coal and CBM coextraction in the Yangquan coalfield, as shown in Figure 6. 


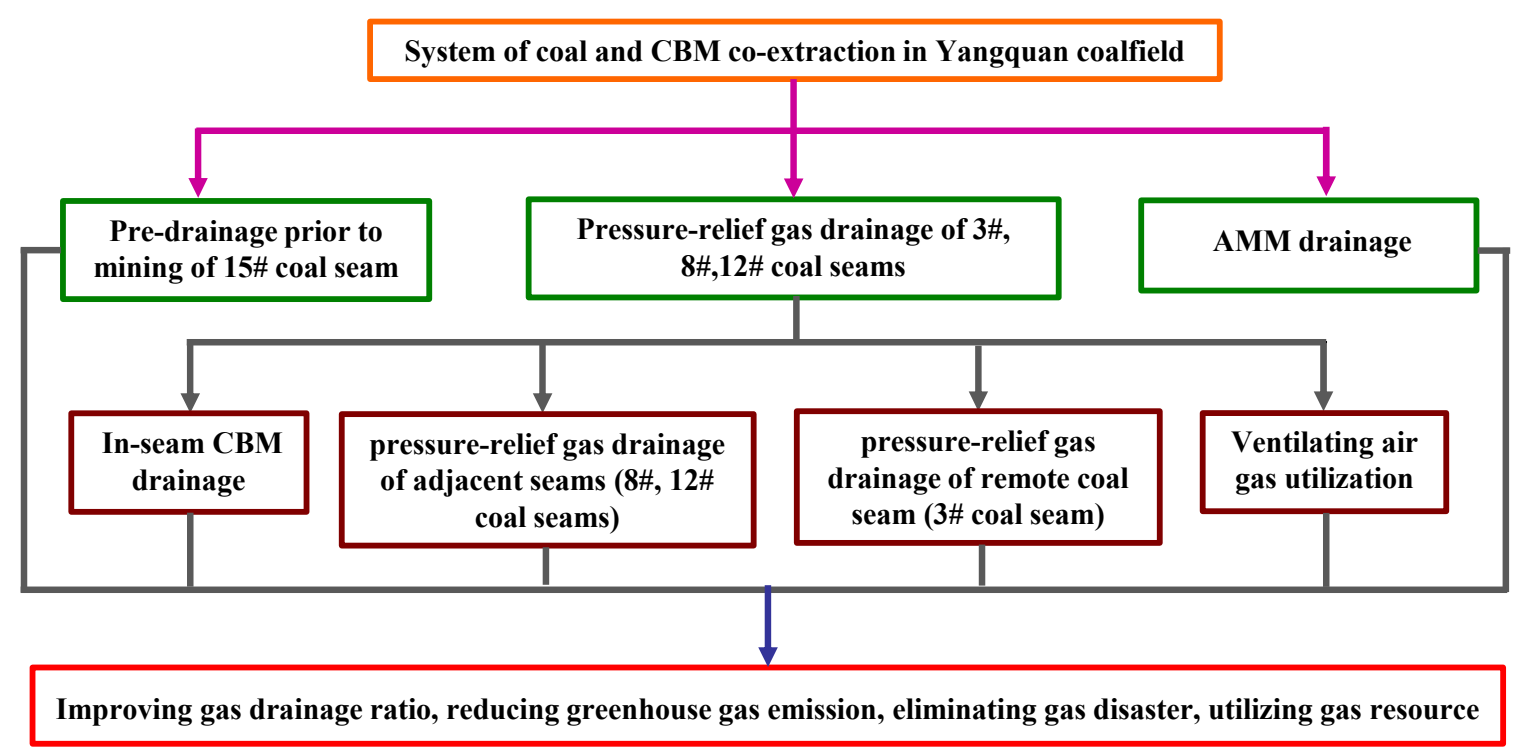

Figure 6. The system of coal and CBM coextraction technology in the Yangquan coalfield.

\section{Coal and CBM Coextraction Technology Based on the Ground Movement in the Yangquan Coalfield}

\subsection{Technologies of Coal and CBM Coextraction for the Yangquan Coalfield}

Through many years of practice, various gas drainage technology modes for coal and CBM coextraction have been developed for the Yangquan coalfield [24], such as: (i) the inseam boreholes technology mode for inseam gas drainage; (ii) the cross-measure boreholes technology mode and the inclined/strike high-level gas drainage roadway technology mode for pressure-relief gas drainage of adjacent seams; (iii) the surface well technology mode for AMM drainage, as shown in Figure 7.

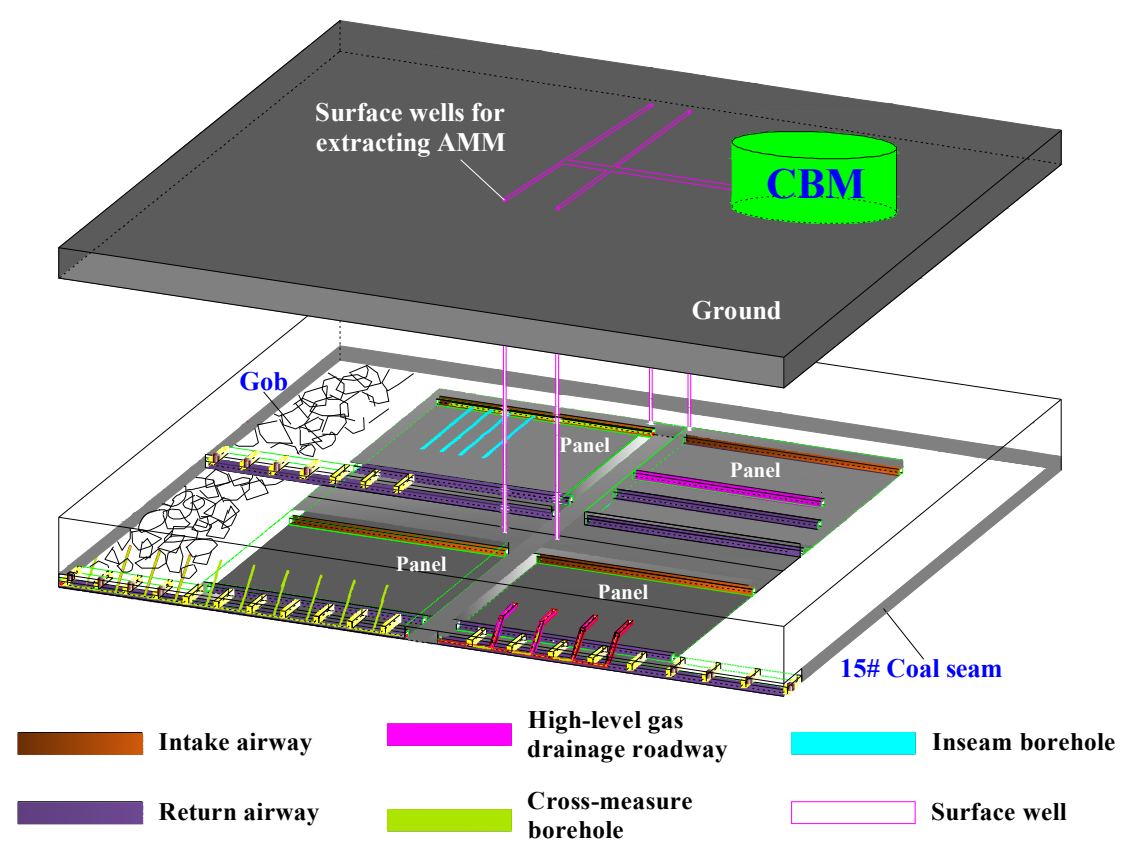

Figure 7. Technology modes of coal and CBM coextraction in the Yangquan coalfield. 


\subsubsection{The Advance Pressure-Relief Gas Drainage Technology for Inseam}

In the process of mining the $15 \#$ coal seam, the "pressure-relief and permeability-increase effect" was used in the abutment pressure-relief zone (see Figure 8) of the working face to extract inseam advance pressure-relief gas in the coal body extending the working face of 3-30 $\mathrm{m}$ (see the III and IV zones in Figure 8) and ensuring no broken gas drainage boreholes among the drainage pipelines $3 \mathrm{~m}$ away from the working face.

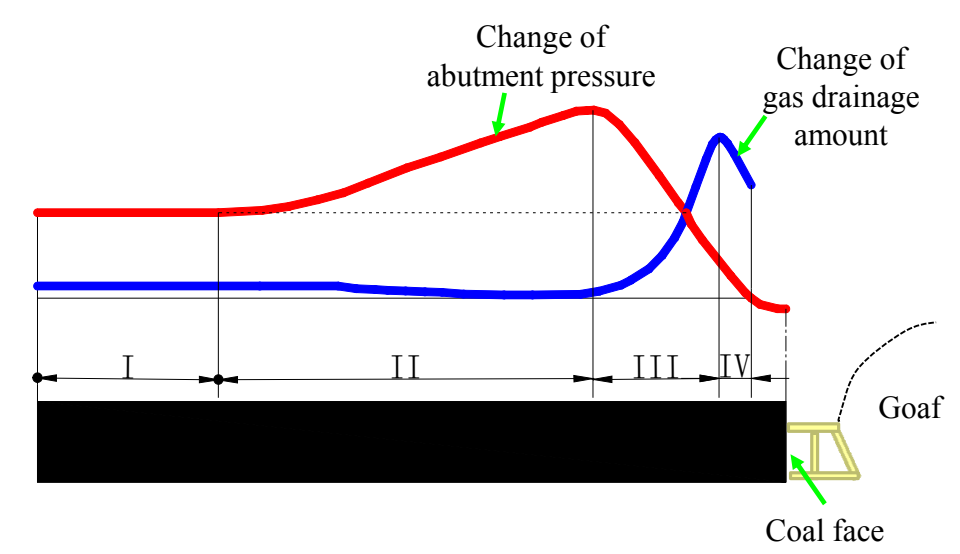

Figure 8. The change relationship between the abutment pressure and the gas drainage for working face in inseam: I-the gas emission zone under initial stress; II-gas emission zone under increased stress; III-gas emission zone under decreased stress; IV-gas emission zone under pressure-relief.

At present, the enhanced pressure-relief gas drainage for inseams was implemented in the Yangquan coalfield, and satisfactory results were obtained. In some gas outburst working faces, the effect was very significant after the enhanced pressure-relief gas drainage, reducing the strength and number of outbursts by $>80 \%$. The average gas drainage amount of $100 \mathrm{~m}$ borehole was $0.051 \mathrm{~m}^{3} / \mathrm{min}$, and the total gas drainage amount was 10.23 million $\mathrm{m}^{3}$.

\subsubsection{The Cross-Measure Borehole Gas Drainage Technology and the Gas drainage Technology of High-Level Gas Drainage Roadway Based on Key Strata Movement for Adjacent Seams}

For the pressure-relief gas drainage of these seams adjacent to 15\# coal seam, we can follow these steps: Firstly, the heights of the "three zones" (namely "gas-way fracture zone", "pressure-relief and desorption zone" and "gas non-desorbed zone" [28], see Figure 9) was discriminated to determine gassy coal seams distribution in the "gas-way fracture zone" and "pressure-relief and desorption zones".

Secondly, according to the coal and gas occurrence characteristics of overburden, the pressure-relief gas emission in the "gas-way fracture zone" and "pressure-relief and desorption zones" were predicted in the mining. Finally, by comparison of the applicable conditions and drainage results of different coal and CBM coextraction technology models, the appropriate coal and CBM coextraction technology and its drainage roadway (drainage borehole) layout parameters were selected with the consideration of the predicted pressure-relief gas emission and layout of the working face in the adjacent seams, as shown in Figure 10. 


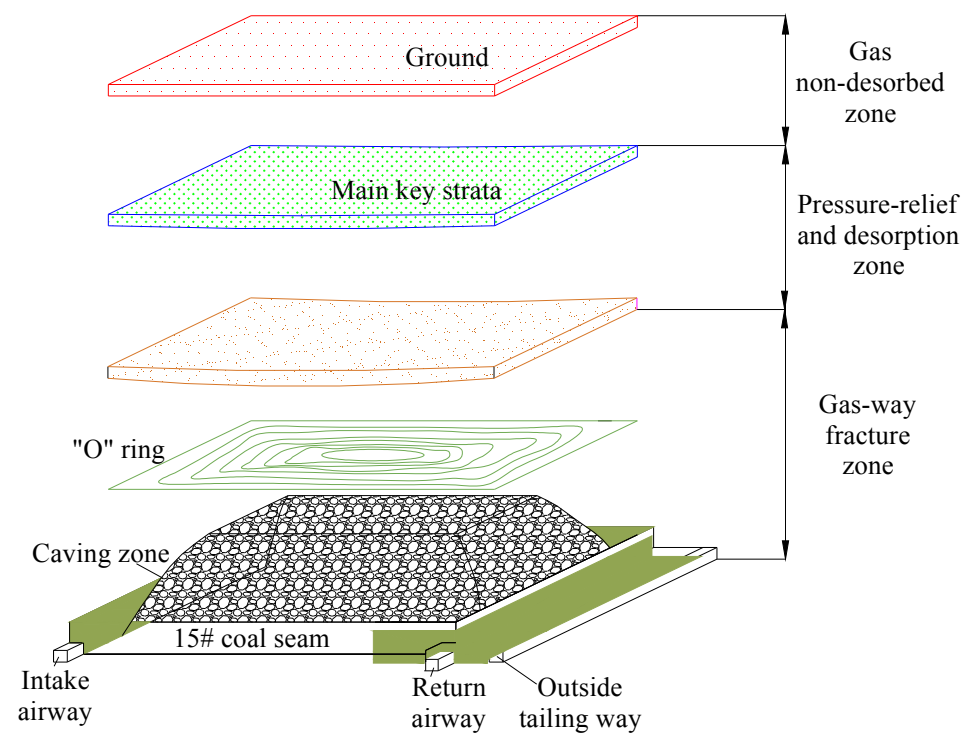

Figure 9. Schematic of "three zone" on pressure-relief gas flow and "O" ring of mining induced crannies in the Yangquan coalfield.

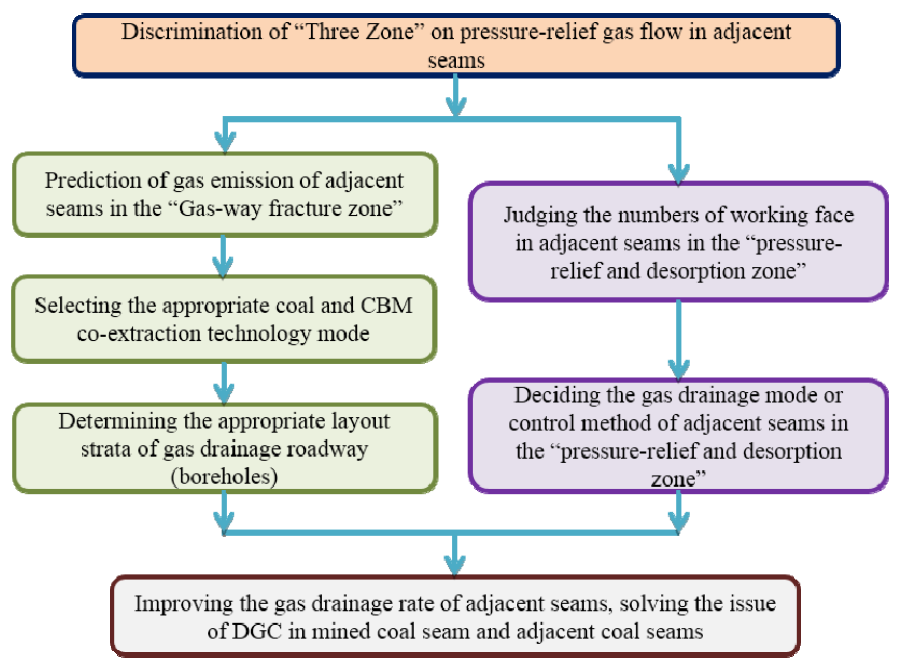

Figure 10. Procedure of gas drainage design of adjacent seams in the Yangquan coalfield.

\section{(1) The Cross-Measure Boreholes Gas Drainage Technology Based on Key Strata Movement}

During a normal stoping period, there are several problems with the process of gas drainage into the adjacent seams. The depth of the boreholes is greater than the periodic weighting pace. As a result, the first drainage borehole will be damaged from roof caving due to periodic weighting, while the next borehole to be emplaced has not yet passed into the fissure zone. Moreover, the numbers of effective drainage boreholes will be limited in the release area of overlying adjacent seams. The gas of adjacent seams will then flood into the removed section of the coal seam and cause the frequent occurrence of gas exceeding the limit of that in the working face. With the advance of the working face, the drainage borehole will be gradually emplaced into the depth of the removed section, and will be gradually compacted. Together with the influence of ground movement, the borehole itself may be cut and blocked, causing the gas drainage to be continuously reduced. The conventional arrangement of gas drainage boreholes for the adjacent seams can be seen in Figure 11. 


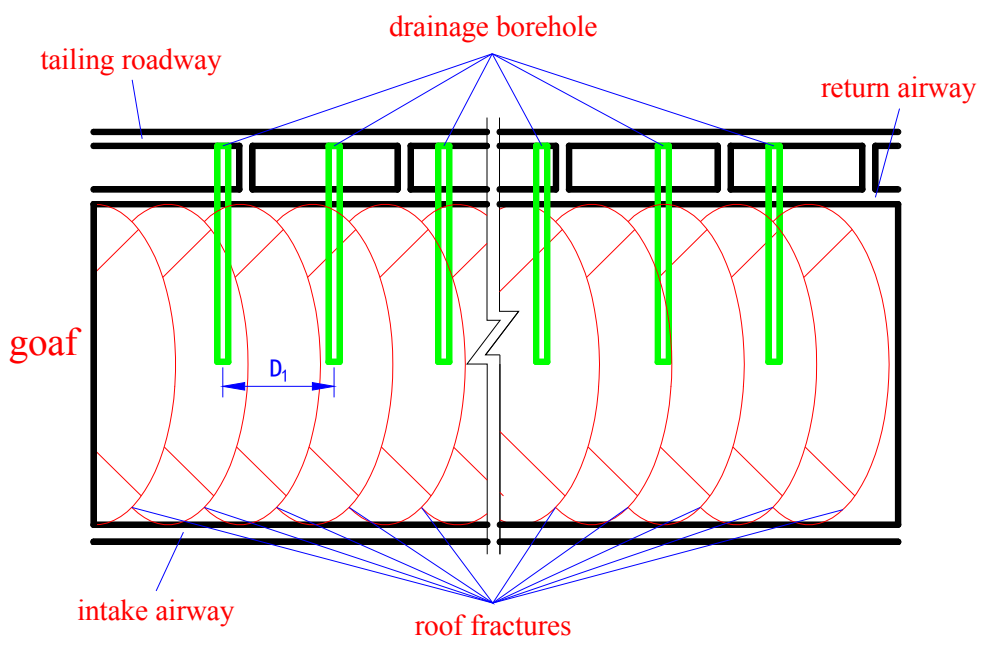

Figure 11. Conventional arrangement of gas drainage boreholes for the adjacent seams.

The practice shows that, the primary and periodic weighting of the working face into which the gas of the adjacent seams floods and the roof of the working face are closely related. Therefore, in order to reach a relatively efficient gas drainage in the adjacent seams, the borehole distance of gas drainage in the adjacent seams along the direction of advance should match the periodic weighting pace of the old roof. This ensures that the efficiency of drainage boreholes matches the weighted roof (Figure 12).

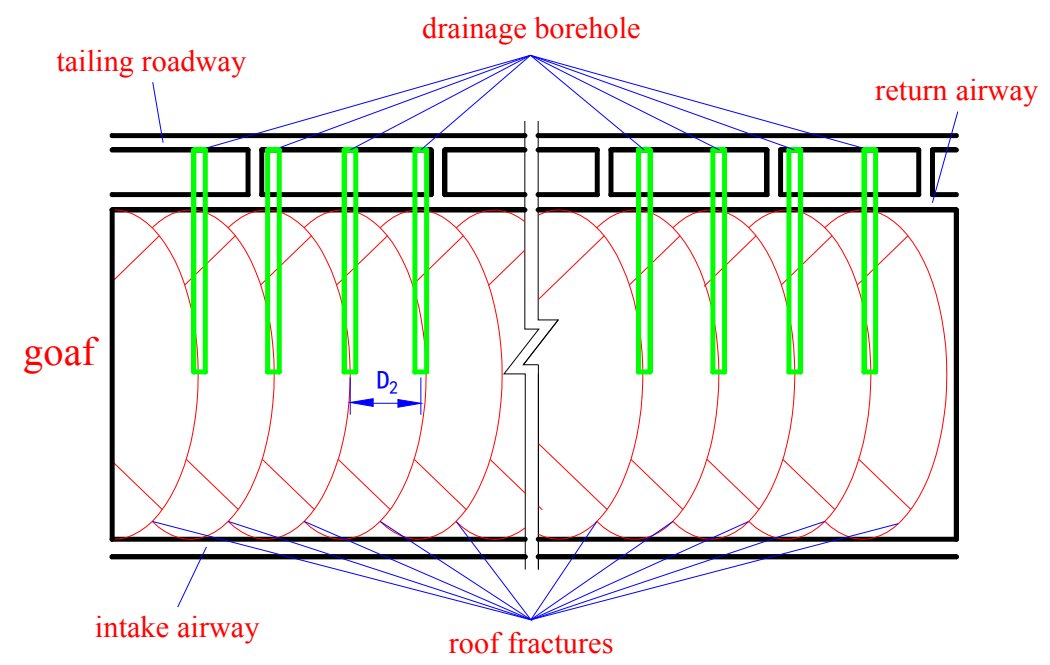

Figure 12. Optimized arrangement of gas drainage boreholes for the adjacent seams.

The cross-measure gas drainage boreholes was creatively experimented and promoted for the Yangquan coalfield, achieving the pressure relief gas drainage rates of $60 \%$ to $70 \%$ for the cross-measure boreholes.

(2) The Gas Drainage Technology of High-Level Gas Drainage Roadway Based on Key Strata movement

The adjacent seam pressure-relief gas is a major source of the gas emissions from the working face in the Yangquan coalfield, therefore, it was necessary to effectively drain this gas to ensure the safety of the working face mining. The high-level gas strike drainage roadway was adopted for the working 
face to drain out the gas released from adjacent seams. The roadway was arranged in the gas-way fracture zone and the "O" ring (see Figure 9) of the mining fracture above the working face, with a big sectional area, which was helpful to collect the gas and reduce the drainage resistance. The arrangement mode of this gas drainage technology in the Yangquan coalfield is shown in Figure 13. The high-level gas drainage roadway was creatively experimented and promoted for the Yangquan coalfield, achieving a maximum gas drainage amount of about $187 \mathrm{~m}^{3} / \mathrm{min}$ for the high-level gas drainage roadway in a single fully mechanized caving face; the pressure relief gas drainage rates of the high-level gas drainage roadway was in the $\sim 80 \%-90 \%$ range.

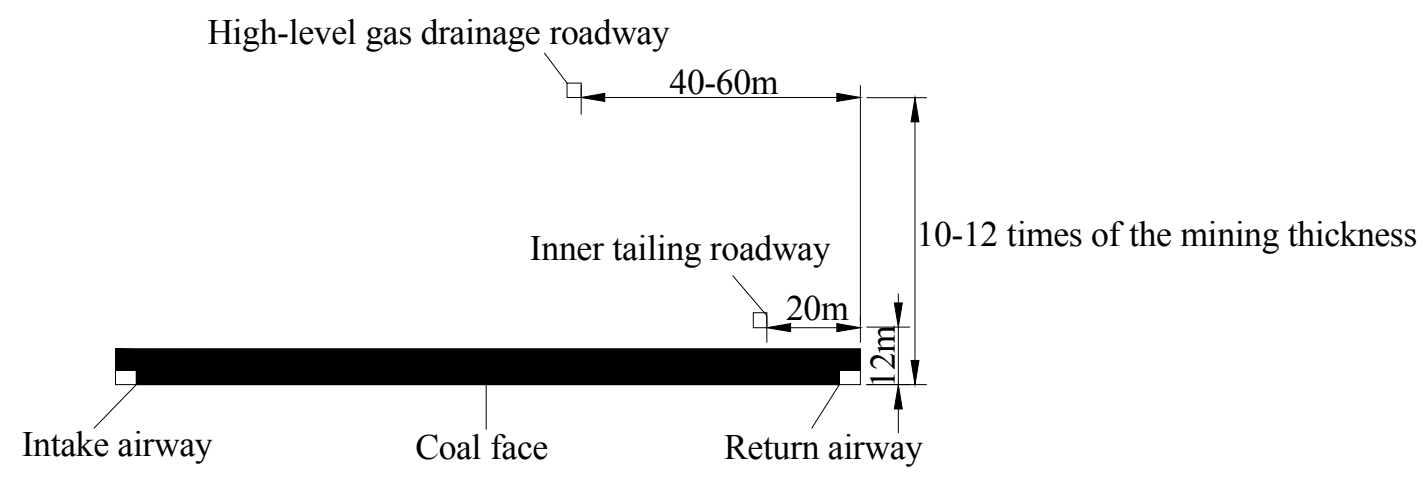

Figure 13. The arrangement of high-level gas drainage roadway for the adjacent seams in Yangquan coalfield.

\subsubsection{Abandoned Mine Methane (AMM) Drainage Technology}

After the extraction of the $3 \#, 8 \#, 12 \#$, and $15 \#$ coal seams and closing the abandoned gob, mining pressure-relief gas would continue to accumulate in the abandoned gob because of the continuous ground movement, forming AMM. The AMM drainage technology is an important part of the coal and CBM coextraction technology in the Yangquan coalfield.

For the AMM drainage in the Yangquan coalfield, first, the AMM sources were analyzed, and an evaluation model was established for the AMM reserves [29], and then the AMM enrichment zone, position and layout of the surface boreholes were predicted to greatly extract the AMM. Yangquan coalfield is leading the engineering practice of using surface wells to extract AMM in China, and the amount of the AMM drainage reached an average of $3504 \mathrm{~m}^{3} /$ day, making AMM an important part of the CBM resources in the Yangquan coalfield. The AMM drainage can promote the capture of the AMM resources and reduce the greenhouse effect of the AMM emissions on the ecological environment.

\subsection{Implementation Results}

With the further applications of these gas drainage technologies in the Yangquan coalfield, a fully mechanized caving face with a gas emission of up to $206 \mathrm{~m}^{3} / \mathrm{min}$ achieved an adjacent seam gas drainage amount of $187 \mathrm{~m}^{3} / \mathrm{min}$ and an annual output of 4 million tons. Moreover, the gas drainage amount showed an increasing trend in the Yangquan coalfield and reached 1.226 billion $\mathrm{m}^{3}$ in 2013 [16], as shown in Figure 14. The safe and efficient mining of the working face were effectively protected with the effective gas drainage. 


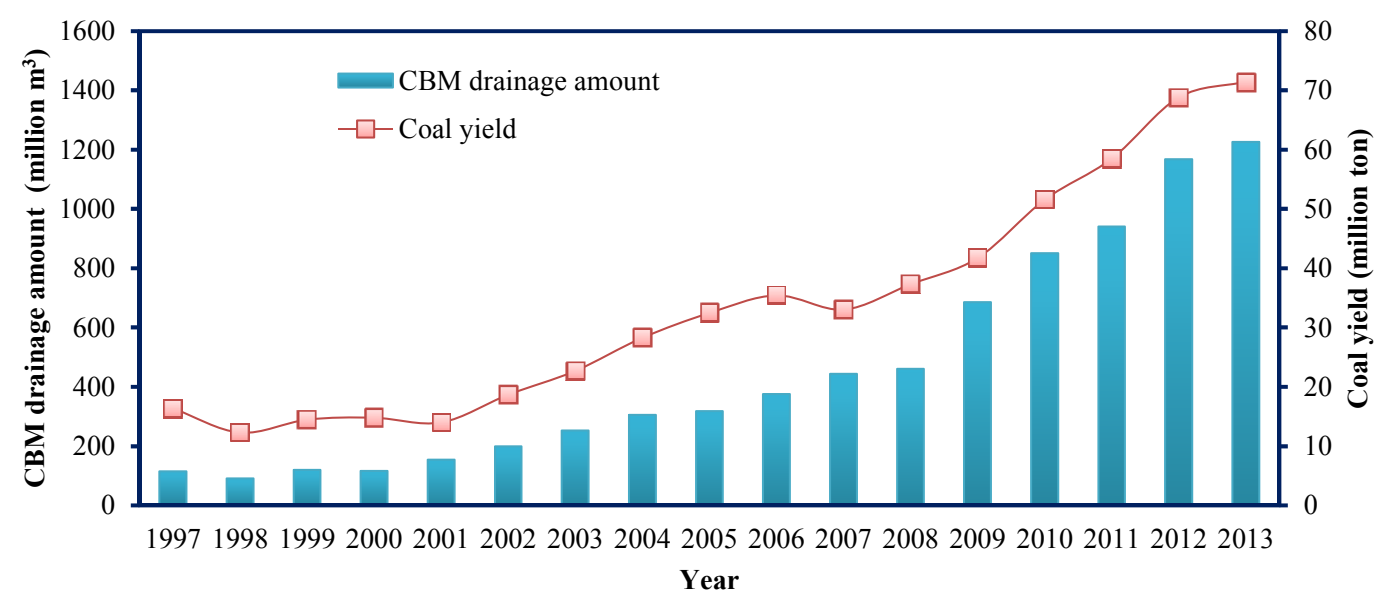

(a)

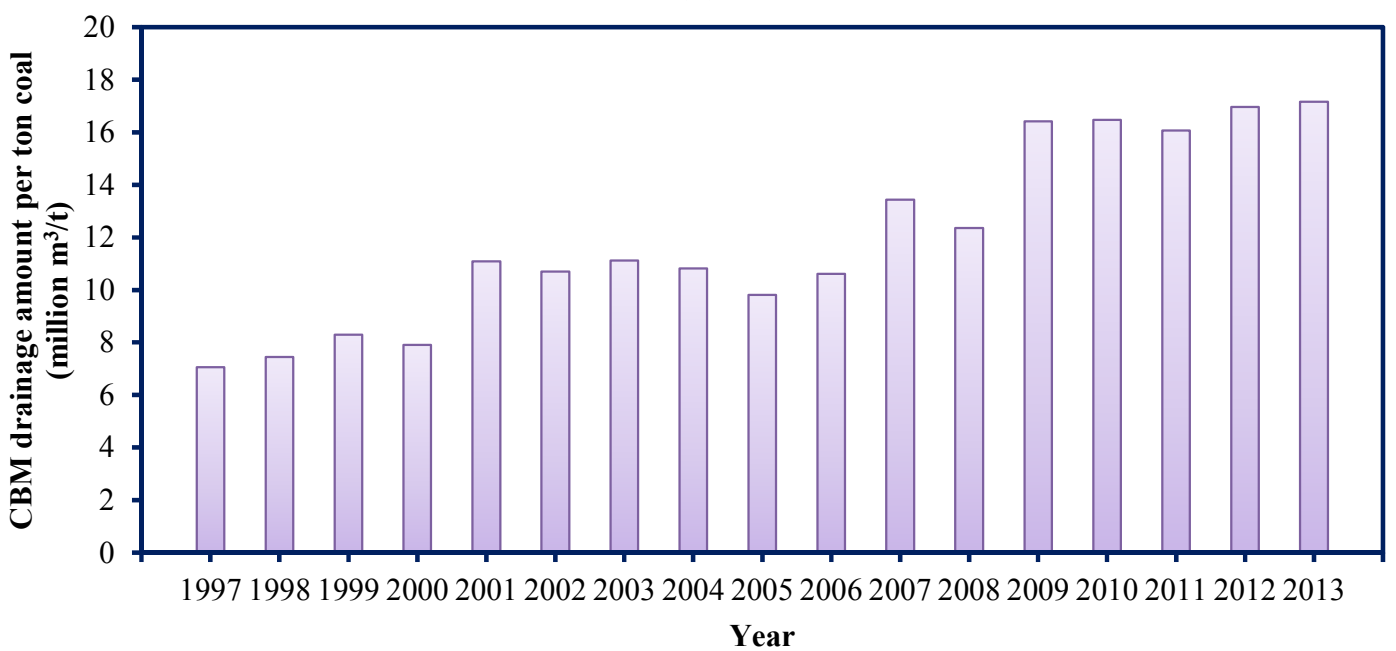

(b)

Figure 14. The gas drainage amount, the gas drainage amount per ton coal and the coal yield of the Yangquan coalfield in recent years: (a) CBM drainage amount and coal yield; (b) CBM drainage amount per ton coal.

\subsection{Analysis and Comparison of the Yangquan Coalfield and Other Typical Mining Areas in China}

Taking the implementation effect of the coal and CBM coextraction in the Yangquan coalfield in 2007 as an example, the comparison of the Yangquan coalfield and other typical Chinese high-gas multiseams mining areas using the gas drainage technology is shown in Figure 15. Compared to the other mining areas, the coal and CBM coextraction technology in the Yangquan coalfield was combined with the coal and gas occurrence characteristics of the Yangquan coalfield. Based on the law of the mining pressure-relief and gas flow caused by the ground movement, and gradually developing distinct coal and CBM coextraction technology with the high-level gas drainage roadway combined of "U + I" and "U + II" ventilation styles as their main gas drainage method according to the characteristics of $15 \#$ coal seam. The Yangquan coalfield achieved a remarkable gas drainage effect with a methane drainage amount of $\sim 50-187 \mathrm{~m}^{3} / \mathrm{min}$ and gas drainage of $\sim 7-270,000 \mathrm{~m}^{3}$ per day for a single roadway. Recently, the Yangquan coalfield became one of the top mining areas in China from the aspect of the pressure-relief gas drainage amount, gas drainage amount per ton coal, and gas utilization amount. 


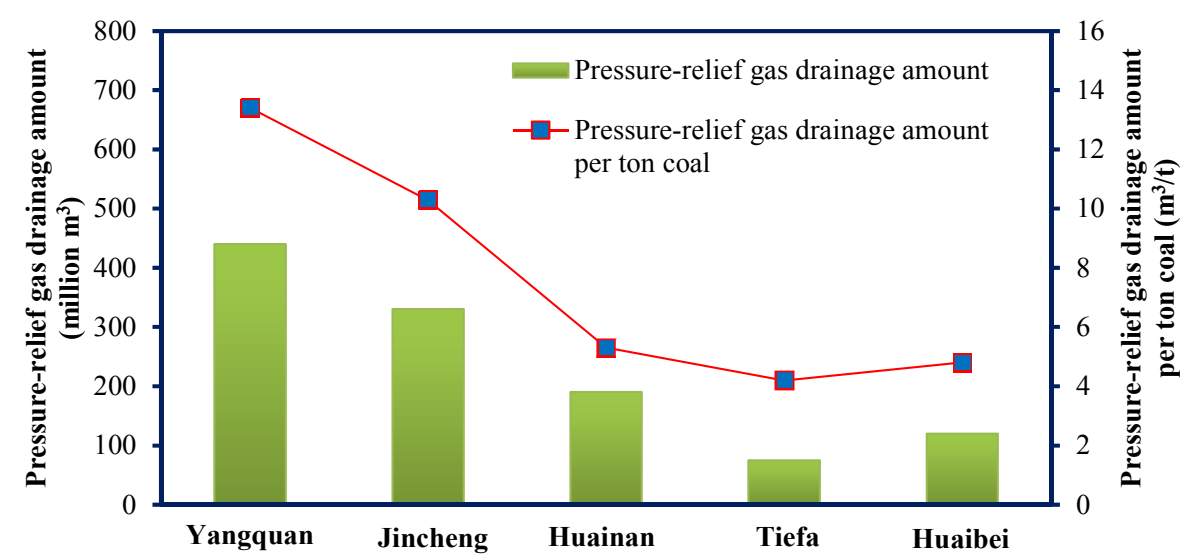

Figure 15. Contrast of the Yangquan coalfield and other Chinese typical high gas multiseams mining areas in pressure-relief gas drainage effect in 2007.

\section{Comprehensive Gas Utilization Technology in the Yangquan Coalfield}

CBM is not only a high heat value pollution-free new energy source, but also is one of the main greenhouse gases polluting the atmospheric environment. If CBM was extracted prior to and in the process of coal mining and comprehensively utilized, it would not only reduce greenhouse gas emissions, but also would promote the efficient and clean use of CBM. At present, the Yangquan coalfield is the mining area with the largest amount of coal mine methane (CMM) drainage in China and is also the mining area with the largest gas emissions to the atmosphere. Therefore, for reducing gas emissions, several gas utilization technologies, mainly including civil gas, gas heating and cooling application and gas power generation technologies were developed in the Yangquan mining area [16]. Among them, gas cooling and heating application technology mainly includes the gas roasting alumina, office gas central air-conditioning, gas firing permanent magnet material, and industrial boiler gas utilization technologies. The Yangquan coalfield has significantly utilized gases due to implementation of several gas utilization technologies and projects since 2007, such as the gas roasting alumina project with production of 80 million ton per year, three gas power generation stations with a total generation amount of $27 \mathrm{MW}$. The gas utilization amount and gas utilization rate in recent years in the Yangquan coalfield are shown in Figure 16.

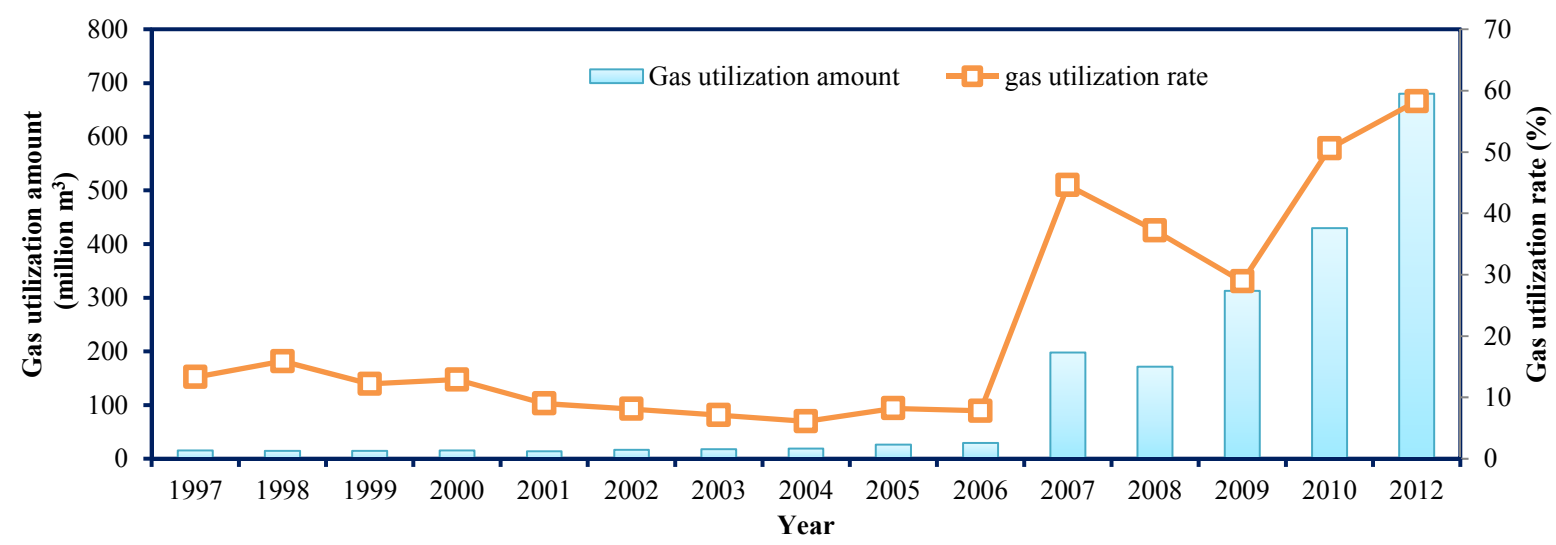

Figure 16. The gas utilization amount, the gas utilization rate and the gas utilization distribution in the Yangquan coalfield. 


\section{Conclusions}

(1) On the basis of key strata theory and ground movement concepts, this research found a method of gas release and migration in the overlying strata, analyzed the principle of coal and gas co-extraction in the Yangquan coalfield, and established an implementation method for the co-extraction of coal and CBM in the Yangquan coalfield.

(2) Based on the occurrence characteristics of coal and gas and the mining pressure-relief gas flow law, a technology for the coal and CBM coextraction with the " $U$ + I' type ventilation and high-level gas drainage roadway" as the main technology was developed for the Yangquan coalfield and achieved safe and highly efficient coal and CBM coextraction. The Yangquan coalfield reached a gas drainage amount in the range $\sim 70,000-270,000 \mathrm{~m}^{3} /$ day for a single high-level gas drainage roadway, with a capacity of $\sim 35-135$ times of a medium CBM surface well $\left(2,000 \mathrm{~m}^{3} /\right.$ day $)$ and achieved $>90 \%$ pressure relief gas drainage rate.

(3) In the Yangquan coalfield, with the development and application of the coal and CBM coextraction technology, the gas drainage effect improved significantly, and the amount of gas drainage increased year after year. In 2013, the pressure-relief gas drainage amount of the Yangquan coalfield reached 1.226 billion $\mathrm{m}^{3}$, improving $78 \%$ compared to that in 2009 .

(4) A multilevel and diversified gas comprehensive utilization technology system including civil gas, gas heating and cooling, and CMM power generation technologies were developed for the Yangquan coalfield to achieve effective gas resources utilization, exploring new clean energy, promoting the reduction of greenhouse gas emissions and also forming a virtuous cycle of "gas utilization improving gas drainage, and consequently ensuring mining safety".

\section{Acknowledgments}

This work was supported by the Fundamental Research Funds for the Central Universities (Grant No. 2012QNA34), Natural Science Foundation of Jiangsu Province of China (Grant No. BK20141131) and a Project Funded by the Priority Academic Program Development of Jiangsu Higher Education Institutions (Grant No. SZBF2011-6-B35).

\section{Author Contributions}

Guozhong $\mathrm{Hu}$ : executive director of this research, he gave a main contribution on this research in the aspect of leading implementation of this research, analyzing the data of investigation and writing this paper. Jialin $\mathrm{Xu}$, Fuxi Zhang, Changchun Zhao: director of this research, they gave a main contribution on this research in the aspect of technically directing implementation of this research, checking the data of investigation and this paper. Wei Qin, Yiran Zhu: they gave a contribution on this research in the aspect of observing the data of investigation and writing this paper.

\section{Conflicts of Interest}

The authors declare no conflict of interest. 


\section{References}

1. Whittles, D.N.; Lowndes, I.S.; Kingman, S.W.; Yates, C.; Jobling, S. Influence of geotechnical factors on gas flow experienced in a UK longwall coal mine panel. Int. J. Rock Mech. Min Sci. 2006, 43, 369-387.

2. Bibler, C.J.; Marshall, J.S.; Pilcher, R.C. Status of worldwide coal mine methane emissions and use. Int. J. Coal Geol. 1998, 35, 283-310.

3. Yuan, L. Theory and practice of integrated pillar-less coal production and methane extraction in multi-seam of low permeability. Eng. Sci. 2009, 11, 72-80.

4. Hu, G.Z.; Wang, H.T.; Fan, X.G.; Hong, S. Mathematical model of coalbed gas flow with Klinkenberg effects in multi-physical fields and its analytic solution. Transp. Porous Media 2009, 76, 407-420.

5. Hu, G.Z.; Huang, X.; Xu, J.L.; Wang, H.T. A co-extraction technology of coal and CBM based on the law of gas advanced relieving pressure of in-seam coalface. Disaster Adv. 2012, 5, 867-872.

6. Saghafi, A. Greenhouse gas emissions from shallow uncovered coal seams. Int. J. Min. Sci. Technol. 2014, 24, 341-344.

7. Zhou, F.D.; Hou, W.W.; Allinson, G.; Wu, J.G.; Wang, J.Z.; Cinar, Y. A feasibility study of ECBM recovery and $\mathrm{CO}_{2}$ storage for a producing $\mathrm{CBM}$ field in Southeast Qinshui Basin, China. Int. J. Greenh. Gas Control 2013, 19, 26-40.

8. Connell, L.D.; Pan, Z.; Camilleri, M.; Meng, S.Z.; Down, D.; Carras, J.; Zhang, W.Z.; Fu, X.K.; Guo, B.G.; Briggs, C.; et al. Description of a $\mathrm{CO}_{2}$ enhanced coal bed methane field trial using a multi-lateral horizontal well. Int. J. Greenh. Gas Control 2014, 26, 204-219.

9. Huang, Y.P.; Zheng, Q.P.; Neng, F.; Aminian, K. Optimal scheduling for enhanced coal bed methane production through $\mathrm{CO}_{2}$ injection. Appl. Energy 2014, 113, 1475-1483.

10. Huang, Y.P.; Rebennack, S.; Zheng, Q.P. Techno-economic analysis and optimization models for carbon capture and storage: A survey. Energy Syst. 2013, 4, 315-353.

11. Sun, M.Y. CBM, a nascent new energy. Sci. Technol. Rev. 1996, 8, 59-61.

12. Perera, M.S.A.; Ranjith, P.G.; Choi, S.K.; Bouazza, A.; Kodikara, J.; Airey, D. A review of coal properties pertinent to carbon dioxide sequestration in coal seams: with special reference to Victorian brown coals. Environ. Earth Sci. 2011, 64, 223-235.

13. Perera, M.S.A.; Ranjith, P.G.; Choi, S.K.; Airey, D. Numerical simulation of gas flow through porous sandstone and its experimental validation. Fuel 2011, 90, 547-554.

14. Perera, M.S.A.; Ranjith, P.G.; Peter, M. Effects of saturation medium and pressure on strength parameters of Latrobe Valley brown coal: Carbon dioxide, water and nitrogen saturations. Energy 2011, 36, 6941-6947.

15. Noackr, K. Control of gas emissions in underground coal mines. Int. J. Coal Geol. 1998, 35, 57-82.

16. Zhu, Y.Z. Development status of mine coalbed methane utilization in Yangquan mining area. Coal Sci. Technol. 2013, 41, 70-72.

17. Li, S.G.; Lin, H.F.; Cheng, L.H. Relation between abutment pressure and relieved gas delivery for fully-mechanized top coal caving. Chin. J. Rock Mech. Eng. 2004, 23, 288-291. 
18. Guo, H.; Yuan, L.; Shen, B.T.; Qu, Q.D.; Xue, J.H. Mining-induced strata stress changes, fractures and gas flow dynamics in multi-seam longwall mining. Int. J. Rock Mech. Min. Sci. 2012, 54, 129-139.

19. Xu, J.L.; Qian, M.G.; Jin, H.W. Study on "coal and coal-bed methane simultaneous extraction" technique on the basis of strata movement. J. China Coal Soc. 2004, 29, 129-132.

20. Qian, M.G.; Xu, J.L.; Miao, X.X. Green Technique in Coal Mining. J. China Univ. Min. Technol. 2003, 32, 343-348.

21. Qian, M.G.; Miao, X.X.; Xu, J.L. Resources and environment harmonics (green) mining and its technological system. J. Min. Saf. Eng. 2006, 23, 1-5.

22. Qu, Q.D.; Xu, J.L.; Qian, M.G. Study on influences of key strata movement on gas emissions of next layers. Chin. J. Rock Mech. Eng. 2007, 26, 1478-1484.

23. Qian. M.G.; Xu, J.L. Study on the "O-shape" circle distribution characteristics of mining-induced fractures in the overlaying strata. J. China Coal Soc. 1998, 23, 466-469.

24. You, H.; Li, B.Y.; Zhang, F.X. The Complex Control Technology of Gas on Fully-Mechanized Top Coal Caving Work Face in the Yangquan Coalfield; China Coal Industry Publishing House: Beijing, China, 2008. (In Chinese)

25. Antonette, K.M. Coalbed methane resource potential and current prospects in Pennsylvania. Int. J. Coal Geol. 1998, 38, 137-159.

26. Romeo, M.F. Coalbed methane: From hazard to resource. Int. J. Coal Geol. 1998, 35, 3-26.

27. Wu, R.L.; Xu, J.L.; Kong, X.; Shi, C.T.; Luo, B.L.; Hu, Y.M.; Li, Y.K. Gas Pressure Relief Rule of Overlying Coal Seam Induced by Fully Mechanized Top Coal Caving in Long Working Face. J. Min. Saf. Eng. 2010, 27, 8-12.

28. Wu, R.L.; Xu, J.L.; Hu, G.Z.; Li, Y.C. The technique of coal and gas simultaneous extraction in coal seam group with low permeability and its case studies. J. Mines Met. Fuels 2011, 59, 349-354.

29. Qin, W.; Xu, J.L.; Hu, G.Z. A method for estimating abandoned gob methane reserves based on the "Three-Zone" theory of relieved gas delivery in coal seams. Energy Sources Part A Recovery Util. Environ Eff. 2013, 35, 585-593.

(C) 2015 by the authors; licensee MDPI, Basel, Switzerland. This article is an open access article distributed under the terms and conditions of the Creative Commons Attribution license (http://creativecommons.org/licenses/by/4.0/). 